\title{
Applicability of molecular simulations for modelling the adsorption of the greenhouse gas CF4 on carbons
}

Article

Accepted Version

Furmaniak, S., Terzyk, A. P., Gauden, P. A., Kowalczyk, P., Harris, P. J.F. and Koter, S. (2013) Applicability of molecular simulations for modelling the adsorption of the greenhouse gas CF4 on carbons. Journal of Physics: Condensed Matter, 25 (1). 015004. ISSN 1361-648X doi:

https://doi.org/10.1088/0953-8984/25/1/015004 Available at https://centaur.reading.ac.uk/30246/

It is advisable to refer to the publisher's version if you intend to cite from the work. See Guidance on citing.

To link to this article DOI: http://dx.doi.org/10.1088/0953-8984/25/1/015004

Publisher: Institute of Physics Publishing

All outputs in CentAUR are protected by Intellectual Property Rights law, including copyright law. Copyright and IPR is retained by the creators or other copyright holders. Terms and conditions for use of this material are defined in the End User Agreement. 


\section{CentAUR}

Central Archive at the University of Reading

Reading's research outputs online 


\title{
Applicability of molecular simulations for modelling the adsorption of the greenhouse gas $\mathrm{CF}_{4}$ on carbons
}

Sylwester Furmaniak ${ }^{1(*)}$, Artur P. Terzyk ${ }^{1}$, Piotr A. Gauden ${ }^{1}$, Piotr Kowalczyk ${ }^{2}$, Peter J.F. Harris ${ }^{3(*)}$, Stanisław Koter ${ }^{4}$

(1) N. Copernicus University, Department of Chemistry, Physicochemistry of Carbon Materials Research Group, Gagarin Street 7, 87-100 Toruń, Poland

(2) Nanochemistry Research Institute, Department of Chemistry, Curtin University of Technology, P.O. Box U1987, Perth, 6845 Western Australia, Australia

(3) Centre for Advanced Microscopy, University of Reading, Whiteknights, Reading RG6 $6 A F$, United Kingdom

(4) N. Copernicus University, Department of Chemistry, Chair of Physical Chemistry and Physicochemistry of Polymers, Gagarin Street 7, 87-100 Toruń, Poland

(*) corresponding authors (to whom correspondence should be addressed)

sf@chem.umk.pl (S.F.)

p.j.f.harris@reading.ac.uk (P.J.F.H.)

\begin{abstract}
Tetrafluoromethane, $\mathrm{CF}_{4}$, is powerful greenhouse gas, and the possibility of storing it in microporous carbon has been widely studied. In this paper we show, for the first time, that the results of molecular simulations can be very helpful in the study of $\mathrm{CF}_{4}$ adsorption. Moreover, experimental data fit to the results collected from simulations. We explain the meaning of the empirical parameters of the supercritical Dubinin-Astakhov model proposed by Ozawa and finally the meaning of the parameter $k$ of the empirical relation proposed by Amankwah and Schwarz.
\end{abstract}

\section{Key words}

Tetrafluoromethane, adsorption, activated carbons, Dubinin-Astakhov model, Monte Carlo simulations 


\section{Introduction}

Perfluorocarbons, due to their high stability and low chemical reactivity have found application in microelectronics for cleaning or printing electronic circuit boards, in semiconductor industry, and also during the process of aluminum production [1,2]. The simplest perfluorocarbon, tetrafluoromethane $\left(\mathrm{CF}_{4}\right)$, is known as a particularly powerful greenhouse gas. It absorbs IR radiation more effectively than $\mathrm{CO}_{2}$. Considering the lifetime of this gas in the atmosphere (50000 years) leads to the conclusion that during a 100 year period $\mathrm{CF}_{4}$ is 6500 more harmful than $\mathrm{CO}_{2}$ [1,2]. Taking this into account there have been many attempts to find a simple and effective method of $\mathrm{CF}_{4}$ storage. Some methods used for this purpose are based on the application of adsorption phenomena, and among adsorbents a crucial role has been played by activated carbons [1,2].

It is well known that activated carbons are widely used for the adsorption of pollutants from gaseous as well as from liquid phases [4-7]. Experimental studies reporting $\mathrm{CF}_{4}$ adsorption data on carbons usually present only isotherms, and/or sometimes a comparison is presented with adsorption of other adsorbates [8-11]. There are however, exceptions. For example Jagiełło et al. [9] considered the possibility of using CF4 for determining the pore size distribution of activated carbons. However, generally, there is a lack of literature data reporting systematic experimental studies on $\mathrm{CF}_{4}$ adsorption on carbons with gradually changed porosity.

The major purpose of this study is to assess the applicability of molecular simulations for prediction of carbon adsorption properties towards the powerful greenhouse gas $\mathrm{CF}_{4}$. Its storage was studied recently using Monte Carlo simulation technique [1,2] however, the results published in the literature were limited only to slit-like micropores and to ideal carbon nanotubes. Therefore, there are no theoretical studies in the literature on $\mathrm{CF}_{4}$ storage on realistic carbon models. This is regrettable, given that realistic models take into account pore connectivity, heterogeneity, disordered carbon structure etc., i.e. fundamental properties of real carbons.

Among realistic carbon structures the Virtual Porous Carbon (VPC) models are the most important [12-15]. Among the major advantages of VPC application we mention well defined porosity and defined chemical composition of carbon surface layer. Thus, contrary to experiment, we know everything about our VPC sample. Additionally, by a simple geometric manipulation we can easily change the porosity of VPC in a systematic way [15].

Another important consideration is that since in real carbons there is an interrelation between the porosity and the chemical composition of the carbon surface layer, it is very hard 
to obtain a series of samples with progressively changed porosity. On the other hand, this is very simple for the case of VPC models. This is why in the present study we collected experimental data of $\mathrm{CF}_{4}$ adsorption on commercially available carbons and additionally, we performed theoretical description of them. Next using a series of VPC, based on models proposed by Harris et al. [16-22] and Monte Carlo simulations we explore the general relationships between theoretical parameters of widely used Dubinin-Astakhov (DA) adsorption model [23-26] and carbon $\mathrm{CF}_{4}$ storage properties. Experimental data fit quiet well to simulation results. Our relations can be very useful for predicting effective $\mathrm{CF}_{4}$ adsorbents. Moreover, we show for the first time for $\mathrm{CF}_{4}$, that the empirical parameter $k$ of the supercritical version of the DA model is strictly related to the pore diameter of the activated carbon sample.

\section{Methodology}

\section{Experimental data of $\mathrm{CF}_{4}$ adsorption on commercial carbons}

The data for $\mathrm{CF}_{4}$ adsorption on commercial carbons are tabulated in the literature. We used the data published by Ahn et al. ( $T=303,323$ and $343 \mathrm{~K}$; this carbon is labelled in our study as AC) [11] and three sets of data published by Jagiełło et al. [8] for carbon molecular sieve Carbosieve $\mathrm{G}(T=258,275$ and $296 \mathrm{~K})$ and activated carbons Westvaco $(T=268,283$ and $297 \mathrm{~K})$ and Maxsorb $(T=268,283$ and $296 \mathrm{~K})$. The sets of adsorption isotherms were described by the supercritical version of the DA adsorption isotherm equation [26]:

$$
a(p, T)=a_{0}(T) \times \exp \left[-\left(\frac{A(p, T)}{E}\right)^{n}\right]
$$

where $a_{0}$ is the maximum adsorption (limited by the volume of pores), $E$ is the characteristic energy of adsorption (formally the product of the characteristic energy and the affinity coefficient), $n$ is the best fit parameter related to the heterogeneity of an adsorbent, and $A$ is the adsorption potential defined as:

$$
A(p, T)=R T \times \ln \frac{p_{s}^{*}}{p}
$$


where $R$ is the universal gas constant and $p_{s}^{*}$ is the apparent saturated vapour pressure for supercritical conditions, calculated by the relation proposed by Amankwah and Schwarz [27]:

$$
p_{s}^{*}=p_{C} \times\left(\frac{T}{T_{C}}\right)^{k}
$$

where $p_{C}=3.75 \mathrm{MPa}$ and $T_{C}=227.51 \mathrm{~K}$ are the critical parameters of $\mathrm{CF}_{4}$, and $k$ is the value characterising an adsorption system. The temperature dependence of maximum adsorption was estimated using the relation proposed by Ozawa et al. [28]:

$a_{0}(T)=a_{0}^{B} \times \exp \left[-\alpha\left(T-T_{B}\right)\right]$

where $a_{0}^{B}$ is the value of maximum adsorption at the boiling point $T_{B}=145.10 \mathrm{~K}$, and $\alpha=0.00251 / \mathrm{K}$ is the thermal expansion coefficient of an adsorbate.

In order to describe the data sets by the DA model (eqs. (1)-(4)), we used the genetic algorithm proposed by Storn and Price [29], applied by us recently for the description of different datasets (see for example [25,26,30-33]). We used exactly the same procedure as described in [26]. The best fit parameters were $a_{0}^{B}, E, n$ and $k$. The goodness of the fit for each isotherm was checked using the value of determination coefficient:

$$
D C_{T}=1-\eta_{T}
$$

where:

$$
\eta_{T}=\frac{\sum_{i}\left(a_{\mathrm{exp}, i}-a_{\text {theo }, i}\right)^{2}}{\sum_{i}\left(a_{\mathrm{exp}, i}-a_{\mathrm{exp}, a v}\right)^{2}}
$$

$a_{\text {exp }, i}$ and $a_{\text {theo,i }}$ denote the experimental (or simulated - see below) and theoretical adsorption values for $i$-th adsorption point, respectively, and $a_{\text {exp,av }}$ is the average experimental (or 
simulated) adsorption value. The global fitting parameter for a branch of isotherms is defined as:

$D C=1-\sqrt{\frac{\sum_{T} \eta_{T}^{2}}{3}}$

where 3 in denominator denotes the number of temperature values. The procedure of standard deviation of the best fit parameters calculation is described in Supplementary data.

\section{Molecular Simulation}

We used a series of VPC described in [34] (selected examples are shown in Fig. 1).The starting structure was S0 (see Fig. 1) composed of fullerene-like fragments (the model proposed by Harris et al.). Additional structures were created by a random incorporation of small carbon fragments. In this way we obtained a series of 10 VPC models with systematically changed porosity (we labelled the structures as: S0, S4, S8, S12, S16, S20, S24, S28, S32, S35). All VPC models were placed in cubic simulation boxes $(4.6 \times 4.6 \times 4.6$ $\mathrm{nm}$ ) with periodic boundary conditions in all three dimensions.

The porosity of VPCs was described using the procedure proposed by Bhattacharya and Gubbins (BG) [35]. During the calculation, for each structure a uniform grid $(100 \times 100 \times 100)$ of points was generated in the box. For each point (located in a pore), the largest sphere containing this point and situated in the pore was found in an iterative way (for details see for example [36,37]). Its diameter corresponds with the size of the pore containing the point. The collection of the data for all the points makes it possible to determine the histogram of pore sizes (i.e. the probabilities of finding the pores having the given effective diameter $\left.\left(d_{e f f}\right)-P\left(d_{e f f}\right)\right)$. The integral curves connected with the histograms were also calculated [37]:

$$
P_{i n t}\left(d_{e f f}\right)=\sum_{d \leq d_{\text {eff }}} P(d)
$$


The $P_{\text {int }}\left(d_{e f f}\right)$ value provides the information what percentage of pores has a diameter not larger than $d_{\text {eff. }}$. The obtained histograms were also used to calculate the average pore diameter of pores accessible for $\mathrm{CF}_{4}$ molecules $\left(d_{e f f, e c c, a v}\right)$ :

$$
d_{e f f, a c c, a v}=\frac{\sum_{d_{e f f} \geq 0.47 \mathrm{~nm}} d_{e f f} \times P\left(d_{\text {eff }}\right)}{\sum_{d_{e f f} \geq 0.47 \mathrm{~nm}} P\left(d_{\text {eff }}\right)}
$$

The lower diameter of pores assumed by us $(0.47 \mathrm{~nm})$ reflects the collision diameter of $\mathrm{CF}_{4}$ molecule (see below).

Adsorption isotherms were simulated using the method proposed by Yan and de Pablo and called hyper parallel tempering Monte Carlo (HPTMC) [38]. For each VPC we used 123 replicas for temperature 283, 298 and $313 \mathrm{~K}$, respectively, and the values of pressure from ca. $1 \mathrm{~Pa}$ up to ca. $6 \mathrm{MPa}$. The HPTMC simulations utilized $1 \times 10^{7}$ cycles (one cycle $=100$ attempts of the change of each replica state by (i) creation, (ii) annihilation or (iii) displacement of a randomly chosen atom with equal probabilities, and one attempt of a configuration swap between a pair of randomly chosen replicas). The first $2 \times 10^{6}$ cycles were discarded to guarantee equilibration.

Each $\mathrm{CF}_{4}$ molecule and each carbon atom building the VPCs were modelled as a simple Lennard-Jones (LJ) centre [39]. The potential energy of interactions was calculated using the truncated LJ potential [39]. The following values of collision diameters $(\sigma)$ and potential well depth $(\varepsilon)$ were used for $\mathrm{CF}_{4}: \sigma_{f f}=0.47 \mathrm{~nm}, \varepsilon_{f f} / k_{B}=152.27 \mathrm{~K}\left(k_{B}-\right.$ is the Boltzmann constant) [1], and for $\mathrm{C}$ atoms: $\sigma_{s s}=0.34 \mathrm{~nm}, \varepsilon_{s s} / k_{B}=28 \mathrm{~K}$ [40]. LorentzBerthelot rule was used for the calculation of parameters for mixed interactions [39].For each type of interactions, the cut-off distance was assumed as equal to $4.5 \times \sigma_{i j}$.

The average number of Ar atoms in each replica $(\langle N\rangle)$ corresponds to the adsorption amount. We calculated the absolute adsorption per unit of carbon mass:

$$
a_{a b s}=\frac{\langle N\rangle}{N_{C} \times M_{C}}
$$

where $N_{C}$ is the number of carbon atoms in a given VPC structure, and $M_{C}$ is the molar mass of carbon. Adsorption excess $\left(a_{e x c}\right)$ was calculated from: 
$a_{e x c}=\frac{\langle N\rangle-\rho_{b u l k} \times V_{a c c}}{N_{C} \times M_{C}}$

where $\rho_{b u l k}$ is the density of gaseous $\mathrm{CF}_{4}$ for given $p$ and $T$, and $V_{a c c}$ is the volume of pores accessible for $\mathrm{CF}_{4}$ in a given VPC structure. $V_{a c c}$ was computed using Monte Carlo integration. The size of pores (limiting their accessibility) was determined analogously as in the above described BG method. In order to illustrate the degree of filling of pores accessible for the adsorbate, the $\mathrm{CF}_{4}$ density in pores was also calculated:

$\rho=\frac{\langle N\rangle}{N_{\mathrm{Av}} \times V_{\mathrm{acc}}}$

where $N_{A v}$ is the Avogadro's number. The isosteric enthalpy of adsorption $\left(q^{s t}\right)$ was calculated from the theory of fluctuations.

Simulated adsorption isotherms were described using the DA model (eqs. (1)-(4)) and the same procedure was applied as used for the description of experimental data.

\section{Results and discussion}

Fig. 2 shows histograms of pore diameters for the studied VPC structures, and the integral pore size distribution curves. All structures are microporous, and one can observe systematic changes in porosity from the structure S0 up to S35. The changes are caused by progressive filling of larger pores by carbon fragments during an MC creation of new structures [34]. One can also see that with the progressive filling of structure S0 by carbon fragments the volume of pores accessible for $\mathrm{CF}_{4}$ molecules decreases (see dashed line in Fig. 2).

Fig. 3 shows the results of the GCMC simulation (for $T=298 \mathrm{~K}$; however, for the remaining temperatures similar regularities are observed). One can observe a systematic decrease in absolute and excess adsorption values with the decrease in average pore diameter. This is the result of the internal VPC structure, i.e. the decrease in pore volume and the rise in the mass of carbon with the rise in microporosity. The observed decrease in $a_{\text {exc }}$ for larger pressures is caused by smaller rise in adsorbed amount than the increase in density of gaseous $\mathrm{CF}_{4}$. 
If one considers the changes in density of adsorbed molecules (Fig. 3c and d) the opposite effect is observed i.e. the density increases in the opposite direction to adsorption, and this is caused by the increasing potential energy with the decrease in pore diameters. This is especially seen on the relative adsorption and adsorption enthalpy plots (Fig. 3e and f).

The influence of porosity on adsorption isotherms and energetics of the process is the smallest at low pressures. At small fillings $\mathrm{CF}_{4}$ molecules are adsorbed inside curved fragments of the fullerene-like structure. Next, at larger pressures, during adsorption on low energetic sites (and during the filling of the whole pore space) one can observe the effect caused by the rise in adsorption potential in smaller pores. Therefore, in smaller pores the volume is utilized by molecules more efficiently, and the pressure necessary to reach a given density decreases from S0 down to the S35 VPC structure (Fig. 3d).

The results of fitting experimental and selected simulated data sets by the DA model (eqs. (1)-(4)) are presented in Fig. 4 and values obtained for the best-fit parameters are collected in Tab. 1. One can observe an excellent goodness of the fit for the experimental as well as simulated data.

The regularities observed on simulated adsorption isotherms are reflected by the values of parameters obtained from the fitting. As one can see from Tab. 1 the decrease in adsorption capacity (limited by the pore volume) from S0 down to S35 structure leads to the decrease in the value of $a_{0}^{B}$ parameter. The decrease in pore diameter leads to a larger characteristic energy of adsorption, at the same time we observe the decrease in the maximum adsorption value. Different types of relationships between $E_{0}$ and pore diameter have been proposed in the literature for adsorbed subcritical and supercritical gases. The simplest of them are inverse relations (see for example [34] and references therein). However, there are no reports showing this type of relations for $\mathrm{CF}_{4}$ adsorption.

As one can observe in Fig. S1 in Supplementary data the data obtained from simulations performed in this study lead to the inverse - type relationship between the both values. Moreover, from this relationship knowing the experimental value of $E_{0}$ one can easily to estimate the pore diameter from experimental data.

As one can also see $k$ and $n$ depend almost linearly on the reverse effective pore diameter of the studied carbon. This is very important, that the empirical parameter of Amankwah and Schwarz relation (eq. (3)) is strictly related with the average diameter of carbon micropores. It is very significant that the experimental data fit well our simulation results. If we compare the simulation with experiment we can see that for the AC carbon 
having, according to the producers, an average pore diameter of $0.59 \mathrm{~nm}$ [11] the values of $E$ and $n(10.89 \mathrm{~kJ} / \mathrm{mol}$ and 2.07 , respectively) are slightly larger than observed for the VPC structure S35 (10.762 $\mathrm{kJ} / \mathrm{mol}$ and 1.848 , respectively), having the smallest average pore diameter (i.e. $0.661 \mathrm{~nm}$ ). Similar $E$ and $n$ values as for carbon $\mathrm{AC}$ are observed for Carbosieve $\mathrm{G}(E=10.863 \mathrm{~kJ} / \mathrm{mol}, n=2.106$, see Tab. 1$)$, therefore in this case we can expect similar pore diameter as for the AC carbon i.e. similar and equal to $0.56 \mathrm{~nm}$ [41]. In contrast, for the two remaining adsorbents (Westvaco and Maxsorb) the pore diameters submitted in the literature are considerably larger (Tab. 1) and this is the reason of considerably smaller $E$ and $n$ values, since the pore size distribution in this case should be wider.

In Fig. 5 we collect all the data considered in this study. As can be observed there is a quite good agreement between simulation and experiment. The data collected in Fig. 5 explain the experimental observation, and allows us to predict the adsorption properties towards $\mathrm{CF}_{4}$ for other carbons. Slightly worse relation between $n$ and inverse pore diameter is probably caused by the fact that $n$, as the heterogeneity measure, should be rather correlated with the width of the pore size distribution. The values of $k$ parameter for experimental data do not fit the simulation results. This is the reason why we omitted this in the manuscript. It is obvious that simple, nanometric scale model of carbon is not a model of real sample studied experimentally. But as it can concluded from obtained results it is a good approach of the real structure.

As it was widely accepted in literature so-called DA plots (i.e. the plots of the isotherms in the linear coordinates of the DA equation) can be useful for the discussion of the mechanism of adsorption. Since the parameter $n$ for all studied systems was calculated by us (see Tab.1) we can easily construct DA plots and they are collected in Figs. S2 and S3 (Supplementary data). Considering the DA plots for selected simulation data (Fig. S2) one can see that they are bimodal i.e. they are composed of two straight lines. The plots become more linear with the rise in temperature and with the rise in the number of small micropores in the system. Thus we can state that the mechanism of primary and secondary micropore filling occurs. In contrast, for experimental data (Fig. S3) apparently we observe the linearity of DA plots. This can be in our opinion caused by the lack of experimental points measured at higher pressures.

As one can easily see, the most promising $\mathrm{CF}_{4}$ adsorbent should possess micropores with a diameter around $0.5 \mathrm{~nm}$, and the diameters should be as homogeneous as possible (i.e. $\mathrm{n}$ should be larger than 2). However, more importantly, there are linear relationships between the empirical parameters of modified DA equation and micropore diameters. Moreover, the 
same linear relationship occurs between $k$ and average pore diameter. In this way, systematic computer simulation studies help to assign the meaning of the empirical parameters.

\section{Conclusions}

The results of this study show that molecular simulations are very powerful for the investigation of adsorption of the greenhouse gas $\mathrm{CF}_{4}$ on carbons. We show for the first time, that the application of VPC models leads to results which are in good agreement with experimental data available in the literature. Experimental data fitted general correlations obtained from Monte Carlo simulations. Importantly, we show not only the general relationships but we are able, for the first time, to explain the physical meaning of the parameters of the empirical DA adsorption isotherm equation. Thus, we show that these parameters are related to the average micropore diameter of the studied carbons.

Our results also lead to the conclusion that the supercritical version of DA model proposed by Ozawa is very powerful tool and should be successful applied for the description of experimental data. Since in the current study we related the empirical parameters of the DA model (used with the empirical Amankwah and Schwarz relation to description of $\mathrm{CF}_{4}$ adsorption data) with the parameters of carbon structure we hope that the results of this study will shed new light on the regularities observed during adsorption of this greenhouse gas.

\section{Acknowledgments}

S.F., A.P.T. and P.A.G. acknowledge the use of the computer cluster at Poznan Supercomputing and Networking Centre (Poznań, Poland) as well as the Information and Communication Technology Centre of the Nicolaus Copernicus University (Torun, Poland). P.K. acknowledges partial support by the Office of Research \& Development, Curtin University of Technology, Grant CRF10084.

\section{References}

[1] Müller E A 2005 Environ. Sci. Technol. 398736

[2] Kowalczyk P and Holyst R 2008 Environ. Sci. Technol. 422931

[3] Bottani E J and Tascón J.M.D. (ed) 2008 Adsorption by Carbons (Amsterdam: Elsevier)

[4] Bansal R Ch and Goyal M 2005 Activated Carbon Adsorption (Boca Raton: Taylor \& Francis) 
[5] Marsh H and Rodríguez-Reinoso F 2006 Activated carbon (Amsterdam: Elsevier)

[6] Tascón J.M.D. (ed) 2012 Novel Carbon Adsorbents (Amsterdam: Elsevier)

[7] Saha B B and K Ch Ng (ed) 2010 Advances in Adsorption Technology (New York: Nova Science Publishers)

[8] Jagiełło J, Bandosz T J, Putyera K and Schwarz J A 1995 J. Chem. Eng. Data 401288

[9] Jagiełło J, Bandosz T J and Schwarz J A 1996 Langmuir 122837

[10] Singh S, Tezel F H and Harlick P J E 2002 Sep. Sci. Technol. 372763

[11] Ahn N-G, Kang S-W, Min B-H and Suh S-S 2006 J. Chem. Eng. Data 51451

[12] Biggs M J and Buts A 2006 Mol. Simul. 32579

[13] Gauden P A, Terzyk A P and Furmaniak S 2008 Wiadomości Chemiczne 62403

[14] Terzyk A P, Furmaniak S, Gauden P A, Harris P J F, Wesołowski R P and Kowalczyk P 2011 Activated Carbon: Classification, Properties and Applications ed Kwiatkowski J F (New York: Nova Science Publishers) pp 355-376

[15] Terzyk A P, Furmaniak S, Gauden P A, Harris P J F and Kowalczyk P 2012 Novel Carbon Adsorbents ed J.M.D. Tascón (Amsterdam: Elsevier) pp 61-104

[16] Harris P J F and Tsang S C 1997 Philos. Mag. A 76667

[17] Harris P J F 1997 Int. Mater. Rev. 42206

[18] Harris P J F, Burian A and Duber S 2000 Philos. Mag. Lett. 80381

[19] Harris P J F 2005 Crit. Rev. Solid State Mater. Sci. 30235

[20] Harris P J F, Liu Z and Suenaga K 2008 J. Phys.: Condens. Matt. 20362201

[21] Harris P J F 2008 Carbon Materials - Theory and Practice ed Terzyk A P, Gauden and P A Kowalczyk P (Kerala, India: Research Signpost) pp 1-14

[22] Harris P J F 2012 J. Mater. Sci. to be published

[23] Stoeckli F 2001 Russ. Chem. Bull. 502265

[24] Kadlec J 2001 Adsorpt. Sci. Technol. 191

[25] Terzyk A P, Furmaniak S, Gauden P A, Harris P J F and Włoch J 2008 J. Phys.: Condens. Matter 20385212

[26] Terzyk A P, Furmaniak S, Wesołowski R P, Gauden P A and Harris P J F 2010 Advances in Adsorption Technology ed B B Saha and K C Ng (New York: Nova Science Publishers) chapter 14

[27] Amankwah K A G and Schwarz J A 1995 Carbon 331313

[28] Ozawa S, Kusumi S and Ogino Y 1976 J. Colloid Interface Sci. 5683

[29] Storn R and Price K 1997 J. Glob. Optim. 11341 
[30] Furmaniak S, Gauden P A, Terzyk A P and Rychlicki G 2008 Adv. Colloid Interface Sci. 13782

[31] Furmaniak S, Terzyk A P, Gołembiewski R, Gauden P A and Czepirski L 2009 Food Res. Int. 421203

[32] Furmaniak S, Terzyk A P and Gauden P A 2011 Drying Technol. 29984

[33] Furmaniak S 2012 Transp. Porous Media 9221

[34] Terzyk A P, Furmaniak S, Gauden P A, Harris P J F, Włoch J and Kowalczyk P 2007 J. Phys.: Condens. Matt. 19406208

[35] Bhattacharya S and Gubbins K E 2006 Langmuir 227726

[36] Furmaniak S, Terzyk A P, Gauden P A, Harris P J F and Kowalczyk P 2009 J. Phys.: Condens. Matt. 21315005

[37] Furmaniak S, Terzyk A P, Gauden P A, Marks N A, Powles R C and Kowalczyk P 2011 J. Colloid Interface Sci. 360211

[38] Yan Q and de Pablo J J 1999 J. Chem. Phys. 1119509

[39] Frenkel D and Smit B 1999 Understanding Molecular Simulation (San Diego: Academic Press)

[40] Steele W A 1974 The Interaction of Gases with Solid Surfaces (Oxford: Pergamon Press)

[41] Hong A, Mariwala R K, Kane M S and Foley H C 1995 Ind. Eng. Chem. Res. 34992

[42] Karanfil T and Kilduff J E 1999 Environ. Sci. Technol. 333217

[43] Takeuchi Y, Hino M, Yoshimura Y, Otowa T, Izuhara H and Nojima T 1999 Sep. Sci. Technol. 1579 
Table 1. The values of the best-fit parameters obtained using DA model (eqs. (1)-(4)) to description of the experimental (a) and simulated data (b). The average pore diameters are also presented (taken from the literature for real carbon samples and calculated from eq. (9) for VPCs)

\begin{tabular}{|c|c|c|c|c|c|c|c|}
\hline Carbon & $\begin{array}{c}d_{a v} \\
{[\mathrm{~nm}]}\end{array}$ & $\begin{array}{c}a_{0}^{B} \\
{[\mathrm{mmol} / \mathrm{g}]}\end{array}$ & $\begin{array}{c}E \\
{[\mathrm{~kJ} / \mathrm{mol}]}\end{array}$ & $n$ & $\boldsymbol{k}$ & $D C_{T}^{*)}$ & $D C$ \\
\hline \multicolumn{8}{|c|}{ (a) experimental data } \\
\hline $\mathbf{A C}$ & $0.59[11]$ & $3.09 \pm 0.35$ & $10.89 \pm 0.56$ & $2.07 \pm 0.15$ & $2.75 \pm 0.17$ & $0.9935 ; 0.9977 ; 0.9886$ & 0.9923 \\
\hline Carbosieve $\mathbf{G}$ & $0.56[41]$ & $8.30 \pm 0.11$ & $10.863 \pm 0.073$ & $2.106 \pm 0.022$ & $4.611 \pm 0.039$ & $0.9996 ; 0.9996 ; 0.9997$ & 0.9996 \\
\hline Westvaco & $1.873[42]$ & $7.1 \pm 1.2$ & $7.12 \pm 0.12$ & $1.66 \pm 0.11$ & $2.70 \pm 0.12$ & $0.9967 ; 0.9951 ; 0.9968$ & 0.9961 \\
\hline Maxsorb & $2.12[43]$ & $18.34 \pm 0.43$ & $6.266 \pm 0.086$ & $1.473 \pm 0.016$ & $2.960 \pm 0.024$ & $0.9998 ; 1.0000 ; 0.9998$ & 0.9999 \\
\hline \multicolumn{8}{|c|}{ (b) simulated data } \\
\hline S0 & 1.197 & $16.598 \pm 0.022$ & $7.387 \pm 0.019$ & $1.3930 \pm 0.0046$ & $2.451 \pm 0.029$ & $0.9999 ; 1.0000 ; 1.0000$ & 1.0000 \\
\hline S4 & 1.000 & $15.291 \pm 0.025$ & $7.970 \pm 0.030$ & $1.5387 \pm 0.0075$ & $2.571 \pm 0.044$ & $0.9999 ; 0.9999 ; 0.9999$ & 0.9999 \\
\hline S8 & 0.888 & $13.858 \pm 0.022$ & $8.632 \pm 0.038$ & $1.666 \pm 0.010$ & $2.643 \pm 0.055$ & $0.9999 ; 0.9999 ; 0.9999$ & 0.9999 \\
\hline S12 & 0.823 & $12.434 \pm 0.019$ & $9.208 \pm 0.041$ & $1.736 \pm 0.011$ & $2.699 \pm 0.060$ & $0.9999 ; 0.9999 ; 0.9999$ & 0.9999 \\
\hline S16 & 0.782 & $11.021 \pm 0.017$ & $9.679 \pm 0.046$ & $1.782 \pm 0.012$ & $2.738 \pm 0.067$ & $0.9998 ; 0 ; 9999 ; 0.9999$ & 0.9999 \\
\hline $\mathbf{S 2 0}$ & 0.745 & $10.319 \pm 0.016$ & $9.997 \pm 0.051$ & $1.819 \pm 0.013$ & $2.768 \pm 0.074$ & $0.9998 ; 0.9999 ; 0.9999$ & 0.9999 \\
\hline S24 & 0.713 & $9.594 \pm 0.015$ & $10.230 \pm 0.051$ & $1.822 \pm 0.014$ & $2.799 \pm 0.076$ & $0.9998 ; 0.9999 ; 0.9999$ & 0.9999 \\
\hline $\mathbf{S 2 8}$ & 0.689 & $8.964 \pm 0.015$ & $10.478 \pm 0.056$ & $1.845 \pm 0.013$ & $2.835 \pm 0.081$ & $0.9998 ; 0.9999 ; 0.9999$ & 0.9999 \\
\hline S32 & 0.673 & $8.311 \pm 0.013$ & $10.663 \pm 0.053$ & $1.833 \pm 0.013$ & $2.932 \pm 0.077$ & $0.9998 ; 0.9999 ; 0.9999$ & 0.9999 \\
\hline S35 & 0.661 & $7.844 \pm 0.013$ & $10.762 \pm 0.057$ & $1.848 \pm 0.014$ & $3.001 \pm 0.083$ & $0.9998 ; 0.9999 ; 0.9999$ & 0.9999 \\
\hline
\end{tabular}

*) - the values arranged according to the rise in temperature 

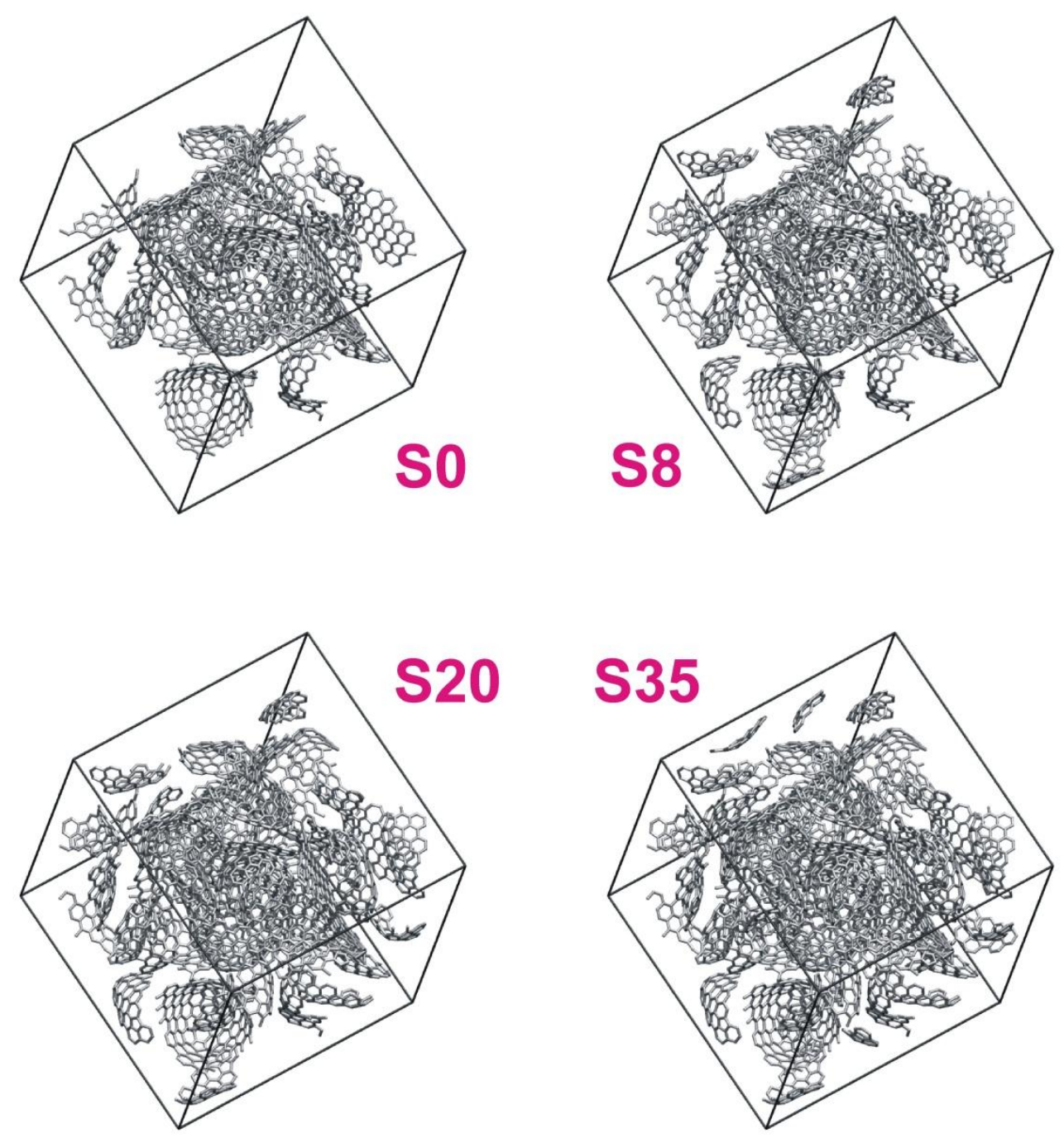

Figure 1. The structure of selected VPC samples (frames reflect the size of the simulation box). 

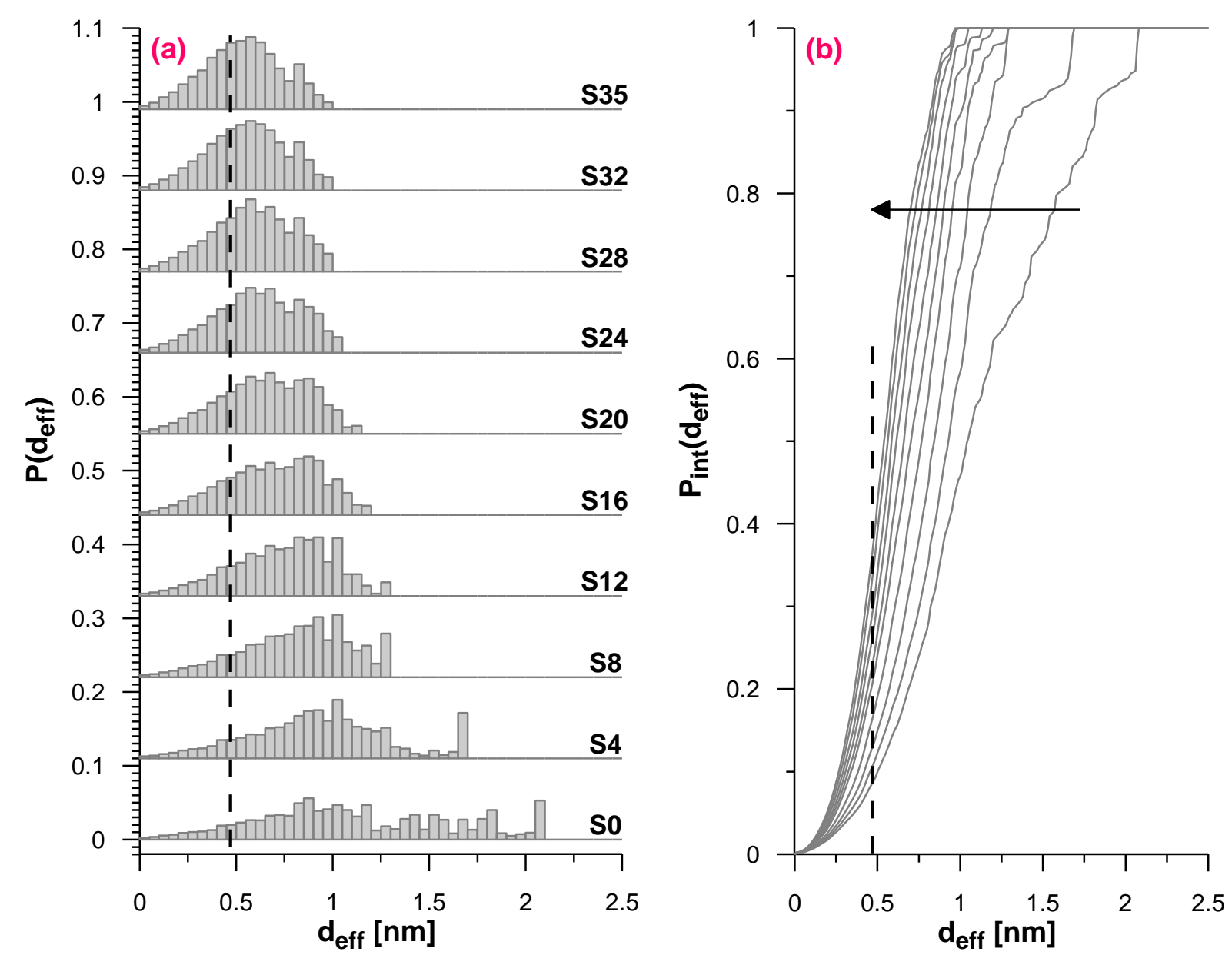

Figure 2. (a) Histograms of pore diameters for virtual porous carbons (dashed line represents the collision diameter of $\mathrm{CF}_{4}$ molecule). (b) The integral curves related to the histograms (the arrow shows the direction of changes from structure S0 up to S35). 

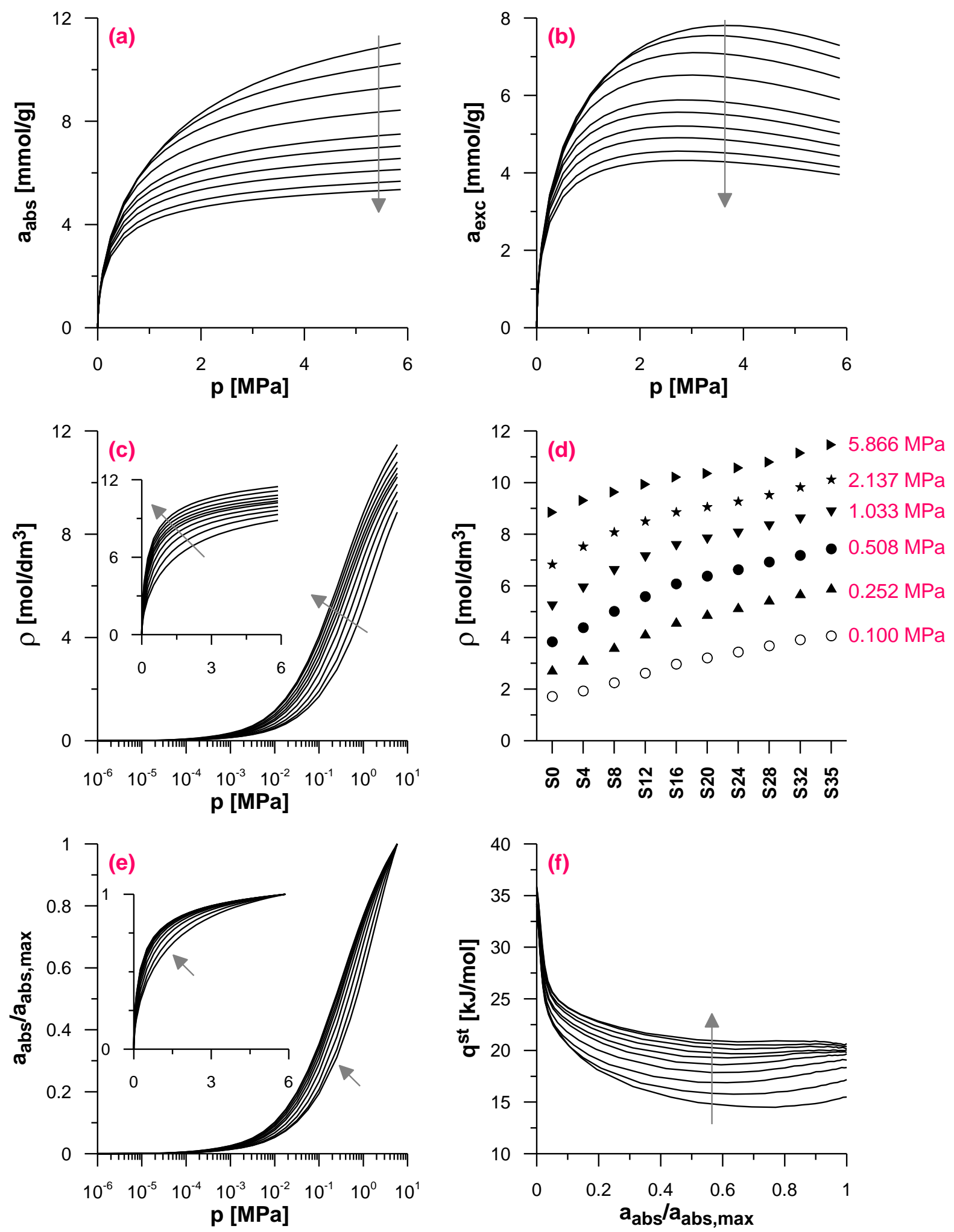

Figure 3. Comparison of simulation results for $T=298$ K. (a) absolute adsorption, (b) excess adsorption, (c) $\mathrm{CF}_{4}$ density in pores, (d) comparison of densities in pores for selected pressures, (e) relative adsorption, (f) isosteric adsorption enthalpy plots. The arrows show the direction of changes from structure S0 up to S35. 

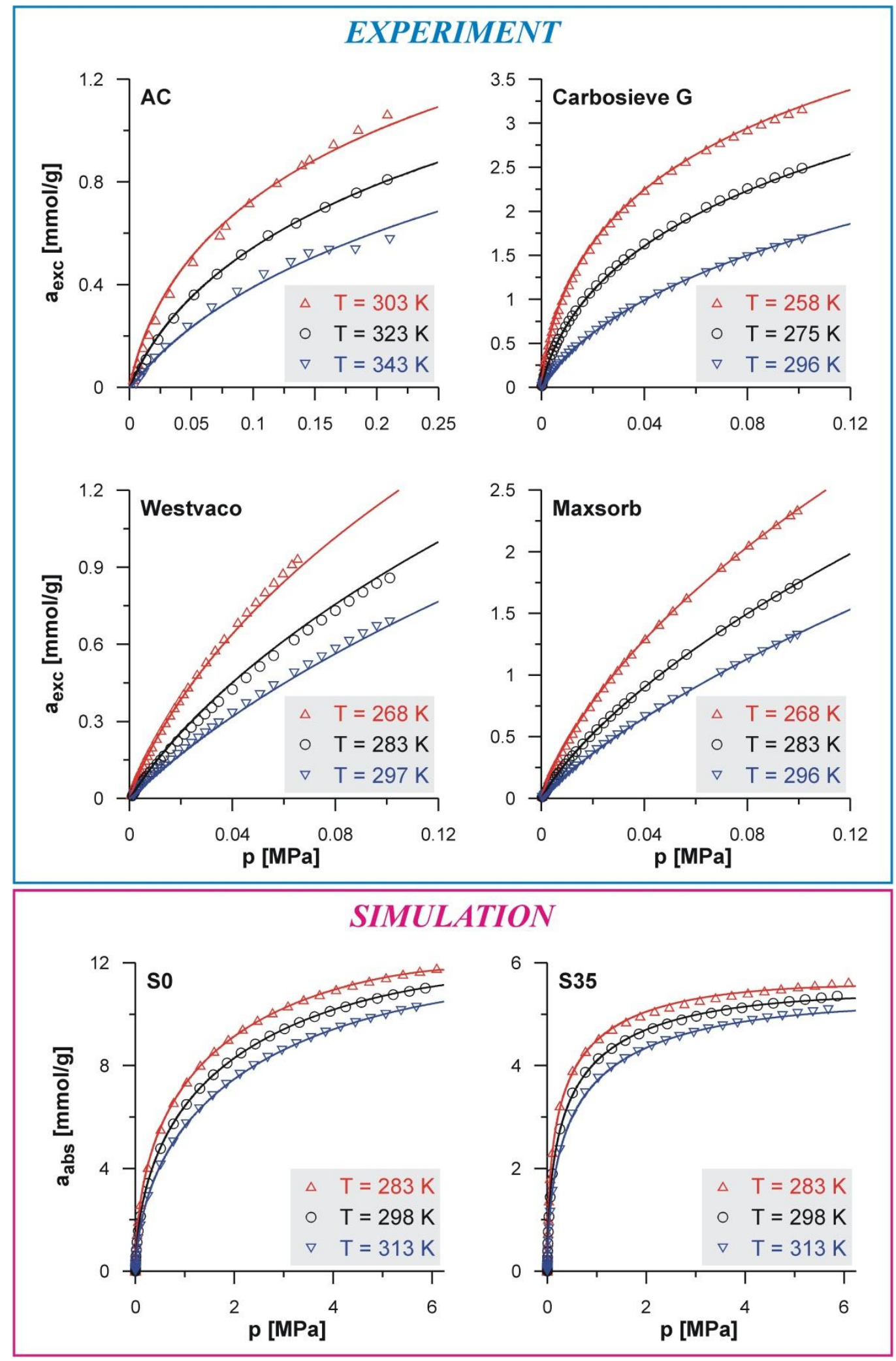

Figure 4. Graphical representation of the fitting of experimental adsorption and selected simulation isotherms using the DA model (eqs. (1)-(4)). Points - experimental and/or simulation data, lines - the model. 

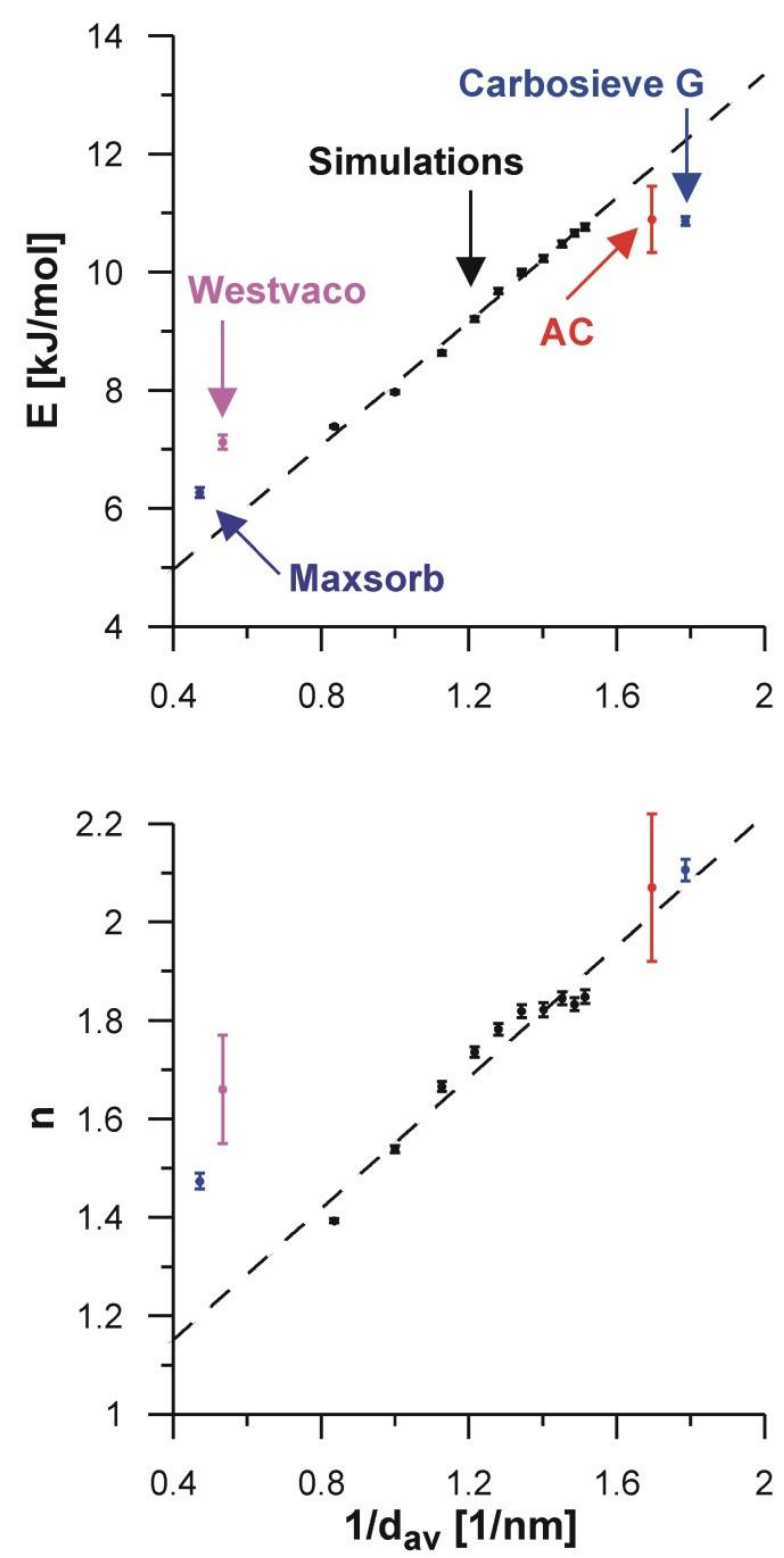

Figure 5. Comparison of characteristic energy an $n$ values for experimental and simulated data (Tab. 1) as a function of reciprocals of the average pore diameters $\left(d_{a v}\right)$. 